\title{
Academic Evaluation in Higher Education
}

Julian Hamann, Forum Internationale Wissenschaft, University of Bonn

Stefan Beljean, Department of Sociology, Harvard University

\section{Definition of academic evaluation}

Academic evaluation is a social process taking place in different arenas in which values, worths, virtues, or meanings are produced, diffused, assessed, legitimated, or institutionalized with respect to academic products and their producers.

\section{Introduction}

The world of academia is permeated with evaluations. Academic processes of evaluation play a central role in both the production and reception of scholarly work as well as for the status of academic entities like scholars, departments, or universities. Some of these evaluations are largely informal, taking place, for example, in small-group interactions. But there is also a wide array of evaluations in academia that are fairly formalized, such as letters of recommendation and peer reviews of journal manuscripts. Rankings of universities according to research performance is among the most standardized forms of evaluation.

Evaluation has a central place in academia because of the crucial role recognition plays in academic fields. Modern academic disciplines are fundamentally status economies. They revolve around the construction and stabilization of recognition via symbolic capital (Bourdieu, 1988). Scholars produce knowledge in the pursuit of recognition from their peers, and recognition, in turn, is the basis for the construction of academic careers. Thus, as a process that ascribes worth, evaluation is also a boundary practice that negotiates, for example, disciplinary turfs, and signals which scholars and ideas are integrated into or excluded from a field (Gieryn, 1983; Lamont and Molnár, 2002). While the study of evaluation processes in academia has traditionally been the purview of the sociology of science (cf. Merton, 1973), it is increasingly studied using analytical tools from the nascent field of the sociology of evaluation and valuation (Lamont, 2012; Zuckerman, 2012).

In this article, we first map out the diversity of academic evaluations, before discussing different analytical perspectives that scholars have drawn on to study evaluation processes in academia. In a fourth section, we discuss scholarship that has pointed to variation in scholarly evaluations across disciplines. Lastly, we put to changes in the social organization of academic evaluation that are the result of recent changes in the governance of academic work as well as technological changes. 


\section{Academic evaluation: a variety of practices and arenas}

Academic evaluation aims at a variety of objects, it is accomplished through a multitude of practices, and it is performed by different actors. Considering this diversity, it is striking that we can identify a number of forms and arenas of evaluation that exist across communities and disciplines.

All academic communities and disciplines are affected by higher education governance regimes that try to assess and audit the output of departments and universities in terms of research performance and societal impact (Martin, 2011). Although this kind of evaluation is becoming increasingly influential in many countries, it is not typically the center of attention of scholarship on academic evaluation. We will discuss some of the effects of this systematic, policy-oriented evaluation towards the end of our article. But then of course, scholars are not only evaluated from the outside. Positioning discourses across all disciplines locate and anchor scholars in knowledge-based communities as well as in bureaucratic positions in institutions (Angermuller, 2013), thereby straddling different logics of academic worlds. The ascription of values and worth in academia largely operates through peer review. This is evident across a number of different institutionalized arenas of evaluation.

Among these arenas are, for example, funding panels. Not only do funding panels exist in all disciplines, often enough several disciplines are congregated in one panel. In order to evaluate proposals for fellowships and research grants (Lamont, 2009), they rank submissions according to criteria of excellence, thus facing the challenge of agreeing on what criteria like 'clarity', 'originality', or 'impact' actually mean (cf. Derrick and Samuel, 2016). Furthermore, there are different arenas in which publications are evaluated. Before publication, editors assess manuscripts for their journals (cf. the overview by Meruane, Vergara, and Pina-Stranger, 2016). Editorial judgments can be understood as a result of the intellectual milieus the editors are situated in, the impressions the editors gained by reading a manuscript, and the discussions in which they rationalize their judgments toward the editorial committee (Hirschauer, 2010). After publication, editors judge articles in case of minor and major errors that need to be met with errata or retractions (Hesselmann et al., 2016), while book reviews provide a critical assessment of newly published books (Riley and Spreitzer, 1970). They examine whether books contribute new knowledge to the field, thus providing an important source of orientation in the face of an ever increasing stock of academic publications (Nicolaisen, 2002).

Although funding and publications are vital resources in all communities and disciplines, evaluative practices and arenas go far beyond that. Appointments of professors, for example, are a consequential arena of academic evaluation where national traditions (Musselin, 2010) influence how different academic criteria like networks and publications (Combes, Linnemer, and Visser, 2008) intertwine with various non-academic criteria like gender (van den Brink and Benschop, 2012). Academic obituaries are another example for a widely neglected arena of evaluation that consecrates deceased colleagues and demonstrates the customary rules according to which academic life-time achievements are narrated and assessed (Hamann, 2016a; Macfarlane and Chan, 2014). 
Last but not least, processes of evaluation also play a crucial role in the very production of scholarly knowledge. While philosophers of science have developed varying accounts of how scientific knowledge is produced and evolves - whether describing an incremental progression toward objective knowledge (Popper, 1972), a conservative authority that prevents change (Feyerabend, 1975), or a mediator for interchanging stages of revolutionary and normal science (Kuhn, 1962) - their theories all acknowledge that scientific inquiry is centrally dependent on the evaluation of epistemic claims. This notion of an intimate connection between evaluation and epistemology has also been confirmed and highlighted by science studies of actual scientific practices (Knorr Cetina, 1999; Latour, 1988).

\section{Analytical perspectives on academic evaluation}

Existing scholarship has examined academic evaluation from a number of analytical perspectives. These perspectives are far from distinct and mutually exclusive, but we want to suggest five tentative strands. First, academic evaluations can be examined from a functionalist perspective, focusing on how well evaluative procedures serve their purposes. Research using this perspective examines, among other things, the validity, reliability, and fairness of judgments (Armstrong, 1997; Bornmann and Daniel, 2005; Reinhart, 2009), and study possible biases (Cole, Cole, and Simon, 1981; Roumbanis, 2016). Power-analytical approaches complement functionalist approaches with a second perspective on academic evaluation. This perspective focuses on dysfunctional effects in terms of structural inequalities like, for example, nepotism in peer review (Sandström and Hällsten, 2008) or unequal opportunities of resource accumulation that follow from it (Hamann, 2016b). The critical intention of this literature is shared by a third perspective that is concerned with the performativity of evaluations and evaluative devices. Scholarship using this analytical perspective has drawn attention to how journal peer review exerts discipline over scholarship (Siler and Strang, 2016; Strang and Siler, 2015; Teplitskiy, 2016), how rankings trigger organizational change (Sauder and Espeland, 2009), or how indicators incite strategic behavior or lead to goal displacement (see the overview in de Rijcke et al., 2015). Fourth, academic evaluations have been studied from a social-constructivist perspective, emphasizing that ideas and personas can be positioned and evaluated differently in various social and historical contexts (Angermuller, 2015; Baert, 2012). This has been illustrated for conceptions of merit and originality (Guetzkow, Lamont, and Mallard, 2004; Tsay et al., 2003), for philosophical ideas (Collins, 2000), or for thinkers like Jacques Derrida (Lamont, 1987) and Richard Rorty (Gross, 2008). Related to this, and fifth, there is a pragmatist perspective on academic evaluation that focuses on the practices reviewers perform to actually reach a consensus on, for example, 'quality' (Hirschauer, 2010; Lamont, 2009). Pragmatist perspectives emphasize the situatedness of evaluative practices, highlighting that evaluations are accomplished in concrete contexts and interactions. However, academic communities and disciplines are also important explanatory factors for evaluative practices. This brings us to the next section. 


\section{Disciplinarity and academic evaluation}

While above we have discusses how most forms and arenas of academic evaluation are institutionalized across all disciplines, we want to emphasize in this section that the criteria of evaluation can differ substantially between and within scholarly communities. We will discuss, first, intradisciplinary aspects of evaluation criteria within disciplines, second, interdisciplinary aspects of evaluation criteria between disciplines, and third, transdisciplinary aspects of evaluation criteria across disciplines.

To begin with, academic communities and disciplines vary on an intradisciplinary spectrum with respect to their internal diversity of evaluation criteria. Members of a discipline can widely agree on the core questions, methods, and theories, or they can be characterized by a plurality of notions of what is relevant, 'good' research. Usually, this continuum spans from the natural sciences, where scholars share most evaluation criteria, over the less paradigmatic social sciences to the even less consensual humanities (Cole, 1983; Evans, Gomez, and McFarland, 2016). The degree to which disciplines share evaluation criteria has become a marker for their value. From Kuhn (1962), who remarkably equals paradigmatic closure with a discipline's maturity, has evolved a powerful symbolic boundary that distinguishes 'hard', paradigmatic, and thus more 'valuable' sciences from 'soft', pre-paradigmatic, and thus less 'valuable' sciences (Peterson, 2015; Smith et al., 2000). The paradigmaticness and scholarly consensus on evaluation criteria can, in turn, influence journal rejection rates (Hargens, 1988).

The diversity of interdisciplinary evaluation criteria, and especially their contestation between different communities and disciplines, has been studied for the social sciences and humanities. One important difference between the two disciplinary clusters is the value of subjectivity in the pursuit of knowledge. Humanists and those social scientists that are influenced by the cultural turn find subjectivity and interpretative skills to be vital for research that is 'good' in terms of being, for example, 'fascinating'. Many social scientists, especially in the quantitative strands, prefer validity and reliability in order to produce research that is 'good' in terms of being 'true' (Lamont, 2009). This finding applies not only to the funding panels studied by Lamont, but also, for example, to book reviews. Reviews in most humanities and social science disciplines have been found to be not only longer and more discursive than in the natural sciences, but also to be critical of both content and style of argument, e.g. by valuing the quality and detail of exposition over demonstration and proof (East, 2011; Hyland, 2004). Furthermore, interdisciplinary differences also become apparent in graduate school admission committees, where economists believe that excellence inheres in what is being evaluated, while philosophers see it as an ideal that reviewers socially construct (Posselt, 2015).

Transdisciplinary differences are illustrated, for example, by varying definitions of the evaluative criteria of 'originality' between social sciences and humanities. Both disciplinary clusters employ a broad definition of 'originality' that includes new perspectives, methods, questions, and arguments. But there are significant differences between the disciplinary clusters. In humanities and history, the most important aspect of originality is an innovative approach, while humanists also value original data. In 
comparison, social scientists privilege originality with respect to methods, and also theories and research topics (Guetzkow, Lamont, and Mallard, 2004).

Arguably, intra-, inter-, and transdisciplinary differences are linked to distinct epistemological cultures (Knorr Cetina, 1981), tribal affiliations and belongings (Becher and Trowler, 2001), and disciplinary rhetoric (Bazerman, 1981). Arenas of evaluation that have to deal with this pluralism illustrate not only the challenges that come with this, but also strategies to overcome them. For instance, interdisciplinary panels do not merely draw on a combination of disciplinary criteria. Rather, hybrid criteria and standards emerge from practices and deliberations between evaluators (Lamont, 2009). Transdisciplinary evaluation is characterized by respect for disciplinary sovereignty and deference to expertise. The respective arenas rely on trust between reviewers of different expertise that their respective judgments are unbiased and disinterested (Lamont, Mallard, and Guetzkow, 2006). Procedures that are supposed to facilitate outcomes perceived as fair include either the application of the same set of general evaluation criteria to different, say, proposals (cf. Collins and Evans, 2002), or the application of criteria that seem appropriate to each proposal in terms of being most relevant to the discipline from which the proposal emanates (Mallard, Lamont, and Guetzkow, 2009). In turn, an obstacle for fair judgments could be that evaluations also have a boundary function. Evaluators use their judgments to reproduce or redefine the boundaries of their respective fields (Posselt, 2016). Evaluative practices that establish fair judgments are not only influenced by the disciplinary composition of panels. Other questions that have an influence include, for example, whether panelists rate or rank proposals, or whether they have an advisory or a decisional role (Lamont and Huutoniemi, 2011).

Apart from the rather deliberative strategies described up to this point, there are also more comprehensive strategies to conceptualize and measure academic quality and research performance by drawing on quantitative techniques. These approaches are increasingly mindful of disciplinary differences. Nonetheless, since criteria for 'good' research and publication practices vary markedly across communities and disciplines, quantitative techniques have been proven to be less appropriate and less acknowledged - in the social sciences and humanities (Mustajoki, 2013; Ochsner, Hug, and Daniel, 2016). For example, customary methods of research performance evaluation are not appropriate for the humanities (Moed, Luwel, and Nederhof, 2002; Nederhof, 2006). Alternative metrics, based on data from the social web and designed to assess non-academic criteria like popularity or media impact, share these limitations (Hammarfelt, 2014). While the academic literature on research quality and performance assessments is distinctly aware of these restrictions, higher education policies do not always share this insight. Most large-scale audits famously ignore and overlook disciplinary differences. We discuss their attempts of academic evaluation in the following section.

\section{Recent developments in the organization of academic evaluation}

The linchpin of academic evaluation has long rested on the notion of academic autonomy and selfgovernance (Whitley, 1984). According to this idea, the work of academics is first and foremost 
evaluated by other scholars. Thus, the primary form of recognition that counts in the world of academia is peer recognition. This is echoed not only in the more classical literature from Popper to Bourdieu that we have cited throughout this contribution. The vital role of peer recognition is also reflected by the central role that peer review has in academic disciplines, whether it is deployed for the distribution of research grants, the allocation of journal space, or the determination of winners of scholarly prizes and awards.

In the last 10-20 years, however, there has been a series of developments that have weakened the relative autonomy of academic fields, and that has added new dominant evaluative procedures and institutions. The most important factor contributing to this trend has probably been the rise of new public management, changing how higher education and its members are governed in many countries across the globe. The main thrust of this new form of governance has been to reduce government funding, and introduce more market-like competition in higher education (e.g., for the case of the United Kingdom, see Deem, Hillyard, and Reed, 2008). Additionally, new public management initiatives have also sought to increase the accountability of universities and its members (Strathern, 2000).

These developments have gone hand in hand with a stronger emphasis on external standards of evaluation in the assessment of scholarly work. One important example is the rise of rankings of academic departments and entire universities, promoted by both media corporations and government agencies (Collins and Park, 2016; Espeland and Sauder, 2016; Hazelkorn, 2014). Another central concomitant has been the growing reliance on quantitative indicators to measure and track scholarly productivity and quality (Burrows, 2012; de Rijcke et al., 2015). Taking the form of bibliometrics or citation indices, these indicators have rapidly diffused into the scientific community, particularly the natural sciences, in part due to changes in the capability of information technology. Research shows that the growing reliance on such indicators has had a host of feedback effects on the content and organization of scholarship (Fochler, Felt, and Müller, 2016; Hamann, 2016b). While many scholars have been very critical of indicators, arguing that they render academic evaluation more mechanical and numerical (Lorenz, 2012), new evaluative procedures and institutions seem to have become an established part of the wide range of academic evaluations.

\section{References}

Angermuller, Johannes. 2013. How to become an academic philosopher. Academic discourse as multileveled positioning practice. Sociología histórica 2013: 263-289.

Angermuller, Johannes. 2015. The Moment of Theory. The Rise and Decline of Structuralism in France and Beyond. London: Continuum.

Armstrong, J. Scott. 1997. Peer review for journals: Evidence on quality control, fairness, and innovation. Science and Engineering Ethics 3: 63-84.

Baert, Patrick. 2012. Positioning Theory and Intellectual Interventions. Journal for the Theory of Social Behaviour 42: 304-324.

Bazerman, Charles. 1981. What Written Knowledge Does: Three Examples of Academic Discourse. Philosophy of the Social Sciences 11: 361-388. 
Becher, Tony, and Paul Trowler. 2001. Academic Tribes and Territories: Intellectual Enquiry and the Cultures of Disciplines. Philadelphia: Open University Press.

Bornmann, Lutz, and Hans-Dieter Daniel. 2005. Selection of research fellowship recipients by committee peer review: Analysis of reliability, fairness and predictive validity of Board of Trustees' decisions. Scientometrics 63: 297-320.

Bourdieu, Pierre. 1988. Homo Academicus. Cambridge: Polity Press.

Burrows, Roger. 2012. Living with the h-index? Metric assemblages in the contemporary academy. The Sociological Review 60: 355-372.

Cole, Stephen. 1983. The Hierarchy of the Sciences? American Journal of Sociology 89: 111-139.

Cole, Stephen, Jonathan R. Cole, and Gary A. Simon. 1981. Chance and consensus in peer review. Science 214: 881-886.

Collins, Francis L., and Gil-Sung Park. 2016. Ranking and the multiplication of reputation: reflections from the frontier of globalizing higher education. Higher Education 72: 115-129.

Collins, Harry H., and Robert Evans. 2002. The third wave of science studies: Studies of expertise and experience. Social Studies of Science 32: 235-296.

Collins, Randall. 2000. The Sociology of Philosophies: A Global Theory of Intellectual Change. Harvard: Harvard University Press.

Combes, Pierre-Philippe, Laurent Linnemer, and Michael Visser. 2008. Publish or peer-rich? The role of skills and networks in hiring economics professors. Labour Economics 15: 423-441.

de Rijcke, Sarah, Paul Wouters, Alex D. Rushforth, Thomas P. Franssen, and Björn Hammarfelt. 2015. Evaluation practices and effects of indicator use-a literature review. Research Evaluation 25: 161-169.

Deem, Rosemary, Sam Hillyard, and Mike Reed. 2008. Knowledge, Higher Education, and the New Managerialism: The Changing Management of UK Universities. Oxford: Oxford University Press.

Derrick, Gemma E., and Gabrielle N. Samuel. 2016. The Evaluation Scale: Exploring Decisions About Societal Impact in Peer Review Panels. Minerva 54: 75-97.

East, John W. 2011. The Scholarly Book Review in the Humanities. An Academic Cinderella? Journal of Scholarly Publishing 43: 52-67.

Espeland, Wendy N., and Michael Sauder. 2016. Engines of Anxiety: Academic Rankings, Reputation, and Accountability. New York: Russell Sage Foundation.

Evans, Eliza D., Charles J. Gomez, and Daniel A. McFarland. 2016. Measuring Paradigmaticness of Disciplines Using Text. Sociological Science 2016: 757-778.

Feyerabend, Paul. 1975. Against Method: Outline of an Anarchist Theory of Knowledge, New Left Books. New York, NY.

Fochler, Maximilian, Ulrike Felt, and Ruth Müller. 2016. Unsustainable Growth, Hyper-Competition, and Worth in Life Science Research: Narrowing Evaluative Repertoires in Doctoral and Postdoctoral Scientists' Work and Lives. Minerva 54: 175-200.

Gieryn, Thomas F. 1983. Boundary-Work and the Demarcation of Science from non-Science: Strains and Interests in Professional Ideologies of Scientists. American Sociological Review 48: 781795.

Gross, Neil. 2008. Richard Rorty: The Making of an American Philosopher. Chicago: Chicago University Press.

Guetzkow, Joshua, Michèle Lamont, and Grégoire Mallard. 2004. What is Originality in the Humanities and the Social Sciences? American Sociological Review 69: 190-212.

Hamann, Julian. 2016a. 'Let us salute one of our kind'. How academic obituaries consecrate research biographies. Poetics 56: 1-14.

Hamann, Julian. 2016b. The visible hand of research performance assessment. Higher Education 72: 761-779.

Hammarfelt, Björn. 2014. Using altmetrics for assessing research impact in the humanities. Scientometrics 101: 1419-1430.

Hargens, Lowell L. 1988. Scholarly consensus and journal rejection rates. American Sociological Review 53: 139-151.

Hazelkorn, Ellen. 2014. Rankings and the Global Reputation Race. New Directions for Higher Education 2014: 13-26. 
Hesselmann, Felicitas, Verena Graf, Marion Schmidt, and Martin Reinhart. 2016. The visibility of scientific misconduct: A review of the literature on retracted journal articles. Current Sociology online first: 1-32.

Hirschauer, Stefan. 2010. Editorial Judgements: A Praxeology of 'Voting' in Peer Review. Social Studies of Science 40: 71-103.

Hyland, Ken. 2004. Disciplinary Discourses. Social Interactions in Academic Writing. Ann Arbor: University of Michigan Press.

Knorr Cetina, Karin. 1981. The Manufacture of Knowledge. An Essay on the Constructivist and Contextual Nature of Science. Oxford: Pergamon Press.

Knorr Cetina, Karin. 1999. Epistemic Cultures. How the Sciences Make Knowledge. Harvard, MA: Harvard University Press.

Kuhn, Thomas S. 1962. The Structure of Scientific Revolutions. Chicago: University of Chicago Press.

Lamont, Michèle. 1987. How to Become a Dominant French Philosopher: The Case of Jacques Derrida. American Journal of Sociology 93: 584-622.

Lamont, Michèle. 2009. How Professors Think. Inside the Curious World of Academic Judgement. Cambridge, MA: Harvard University Press.

Lamont, Michèle. 2012. Toward a Comparative Sociology of Valuation and Evaluation. Annual Review of Sociology 38: 201-221.

Lamont, Michèle, and Katri Huutoniemi. 2011. "Comparing Customary Rules of Fairness: Evaluative Practices in Various Types of Peer Review Panels." In Social Knowledge in the Making, edited by Charles Camic, Neil Gross and Michèle Lamont, 209-232. Chicago: University of Chicago Press.

Lamont, Michèle, Grégoire Mallard, and Joshua Guetzkow. 2006. Beyond Blind Faith: Overcoming the Obstacles to Interdisciplinary Evaluation. Research Evaluation 15: 43-55.

Lamont, Michèle, and Virág Molnár. 2002. The Study of Boundaries in the Social Sciences. Annual Review of Sociology 28: 167-195.

Latour, Bruno. 1988. Science in Action. How to Follow Scientists and Engineers through Society. Harvard: Harvard University Press.

Lorenz, Chris. 2012. If You're So Smart, Why Are You under Surveillance? Universities, Neoliberalism, and New Public Management. Critical Inquiry 38: 599-629.

Macfarlane, Bruce, and Roy Y. Chan. 2014. The last judgement: exploring intellectual leadership in higher education through academic obituaries. Studies in Higher Education 39: 294-306.

Mallard, Grégoire, Michèle Lamont, and Joshua Guetzkow. 2009. Fairness as appropriateness: negotiating epistemological differences in peer review. Science, Technology, \& Human Values 34: 573-606.

Martin, Ben R. 2011. The Research Excellence Framework and the 'impact agenda': are we creating a Frankenstein monster? Research Evaluation 20: 247-254.

Merton, Robert K. 1973. The Sociology of Science. Theoretical and Empirical Investigations. Chicago: University of Chicago Press.

Meruane, Omar Sabaj, Carlos Gonzáles Vergara, and Álvaro Pina-Stranger. 2016. What We Still Don't Know About Peer Review. Journal of Scholarly Publishing 47: 180-212.

Moed, Henk F., Marc Luwel, and Anton J. Nederhof. 2002. Towards Research Performance in the Humanities. Library Trends 50: 498-520.

Musselin, Christine. 2010. The market for academics. New York, NY: Routledge.

Mustajoki, Arto. 2013. "Measuring Excellence in Social Sciences and Humanities: Limitations and Opportunities." In Global University Rankings. Challenges for European Higher Education, edited by Tero Erkkilä, 147-165. Houndmills, Basingstoke: Palgrave Macmillan.

Nederhof, Anton J. 2006. Bibliometric Monitoring of Research Performance in the Social Sciences and the Humanities: A Review. Scientometrics 66: 81-100.

Nicolaisen, Jeppe. 2002. The scholarliness of published peer reviews: a bibliometric study of book reviews in selected social science fields. Research Evaluation 11: 129-140.

Ochsner, Michael, Sven E. Hug, and Hans-Dieter Daniel, eds. 2016. Research Assessment in the Humanities. Towards Criteria and Procedures. Dordrecht: Springer.

Peterson, David. 2015. All That Is Solid. Bench-Building at the Frontiers of Two Experimental Sciences. American Sociological Review 80: 1201-1225. 
Popper, Karl R. 1972. Objective Knowledge. An Evolutionary Approach. Oxford: Clarendon Press.

Posselt, Julie R. 2015. Disciplinary Logics in Doctoral Admissions: Understanding Patterns of Faculty Evaluation. The Journal of Higher Education 86: 807-833.

Posselt, Julie R. 2016. Inside Graduate Admissions. Merit, Diversity, and Faculty Gatekeeping. Cambridge, MA: Harvard University Press.

Reinhart, Martin. 2009. Peer Review of Grant Applications in Biology and Medicine: Reliability, Fairness, and Validity. Scientometrics 81: 789-909.

Riley, Lawrence E., and Elmer A. Spreitzer. 1970. Book Reviewing in the Social Sciences. The American Sociologist 5: 358-363.

Roumbanis, Lambros. 2016. Academic judgments under uncertainty: A study of collective anchoring effects in Swedish Research Council panel groups. Social Studies of Science, online first.

Sandström, Ulf, and Martin Hällsten. 2008. Persistent nepotism in peer-review. Scientometrics 74: 175189.

Sauder, Michael, and Wendy N. Espeland. 2009. The Discipline of Rankings: Tight Coupling and Organizational Change. American Sociological Review 74: 63-82.

Siler, Kyle, and David Strang. 2016. Peer Review and Scholarly Originality. Let 1,000 Flowers Bloom, but Don't Step on Any. Science, Technology, \& Human Values online first.

Smith, Laurence D., Lisa A. Best, Alan D. Stubbs, John Johnston, and Andrea B. Archibald. 2000. Scientific Graphs and the Hierarchy of the Sciences: A Latourian Survey of Inscription Practices. Social Studies of Science 30: 73-94.

Strang, David, and Kyle Siler. 2015. Revising as Reframing. Original Submissions versus Published Papers in Administrative Science Quarterly, 2005 to 2009. Sociological Theory 33: 71-96.

Strathern, Marilyn. 2000. The Tyranny of Transparency. British Educational Research Journal 26: 309321.

Teplitskiy, Misha. 2016. Frame Search and Re-search: How Quantitative Sociological Articles Change During Peer Review. The American Sociologist 47: 264-288.

Tsay, Angela, Michèle Lamont, Andrew Abbott, and Joshua Guetzkow. 2003. From character to intellect: changing conceptions of merit in the social sciences and humanities, 1951-1971. Poetics 2003: 23-49.

van den Brink, Marieke, and Yvonne Benschop. 2012. Gender practices in the construction of academic excellence: Sheep with five legs. Organization 19: 507-524.

Whitley, Richard D. 1984. The Intellectual and Social Organization of the Sciences. Oxford: Oxford University Press.

Zuckerman, Ezra W. 2012. Construction, Concentration, and (Dis)Continuities in Social Valuations. Annual Review of Sociology 38: 223-245. 